\title{
Mild stunting is associated with higher body fat: study of a low-income population
}

\author{
Ana Paula Grotti Clemente, ${ }^{1}$ Carla Danusa da Luz Santos, ${ }^{2}$ Vinicius J. B. Martins, ${ }^{1}$ \\ Ana Amélia Benedito-Silva, ${ }^{3}$ Maria Paula Albuquerque, ${ }^{4}$ Ana Lydia Sawaya ${ }^{5}$
}

\begin{abstract}
Objective: To test if individuals having height-for-age $z$ scores between -2 and -1 present higher body fat percentage and, therefore, should not be categorized as having normal nutritional status.

Methods: The study involved 96 individuals ( 52 boys and 44 girls); $57 \%$ of whom had already attained puberty. Body composition was analyzed by dual energy X-ray absorptiometry.

Results: The percentage of abdominal body fat in pre-pubertal stunted girls was higher $(27.4 \% ; p=0.01)$ in comparison with their non-stunted counterparts (20.6\%). Similar differences in abdominal fat content (\%) were observed for pubertal stunted and non-stunted girls and boys ( 37.6 and $29.8 \%$, respectively, $p=0.01 ; 24.6$ and $15.7 \%, p=0.01$, respectively). The percentages of total body fat percent in pre-pubertal stunted girls and pubertal stunted boys ( 29.9 and $24.5 \%, p=0.03 ; 26.3$ and $18.1 \%, p=0.01$, respectively) were higher than those of their non-stunted counterparts. Non-stunted groups showed lower waist circumferences.

Conclusion: Adolescents with mild stunting exhibit alterations in body composition indicating increased risk of metabolic diseases.
\end{abstract}

J Pediatr (Rio J). 2011;87(2):138-144: Height, malnutrition, overweight, adolescent, poverty.

\section{Introduction}

In many developing regions, the prevalence of maternal and child undernutrition remains unacceptably high, and represents a primary cause of elevated levels of disease burden and mortality. According to an assessment of 388 national surveys from 139 countries, some $20.2 \%$ (112 million) of children under 5 years of age and living in developing countries were classified in 2005 (according to World Health Organization [WHO] child growth standards) as underweight (weight-for-age z score [WAZ] < -2 standard deviations [SD]), whilst 32\% (178 million) were categorized as stunted (height-for-age $\mathrm{z}$ score $[\mathrm{HAZ}]<-2 \mathrm{SD}$ ). ${ }^{1}$
Large-scale epidemiological studies have revealed that children who had suffered retarded growth in the uterus or during early infancy exhibit an increased risk of developing a non-communicable disease in adulthood. ${ }^{2-4}$ The overall level of risk is apparently dependent on the environmental conditions in which the children grow and develop, ${ }^{2-5}$ and may be exacerbated by the onset of obesity in later life. ${ }^{5-7}$

A number of studies have shown that early undernutrition is associated with overweight, especially with increased abdominal fat. Respiratory quotient (RQ) and total energy expenditure in stunted and non-stunted children were

1. Doutoranda, Programa de Pós-Graduação em Endocrinologia Clínica, Universidade Federal de São Paulo (UNIFESP), São Paulo, SP, Brazil.

2. Doutoranda, Programa de Pós-Graduação em Pediatria e Ciências Aplicadas à Pediatria, UNIFESP, São Paulo, SP, Brazil.

3. Doutora. Professora, Escola de Artes Ciências e Humanidades, Universidade de São Paulo, São Paulo, SP, Brazil.

4. Pediatra, Centro de Recuperação e Educacãa Nutricional, São Paulo, SP, Brazil.

5. Professora livre-docente, Departamento de Fisiologia, UNIFESP, São Paulo, SP, Brazil.

No conflicts of interest declared concerning the publication of this article.

Financial support: Fundação de Amparo à Pesquisa do Estado de São Paulo (Processo 06/56218-0).

Suggested citation: Clemente AP, Santos CD, Martins VJ, Benedito-Silva AA, Albuquerque MP, Sawaya AL. Mild stunting is associated with higher body fat: study of a low-income population. J Pediatr (Rio J). 2011;87(2):138-144.

Manuscript submitted Set 09 2010, accepted for publication Nov 172010

doi:10.2223/JPED.2071 
compared in a cross-sectional study carried out by Hoffman et al. $^{3}$ in low-income areas within the city of São Paulo. The stunted group exhibited significantly higher RQ and, consequently, lower fat oxidation, demonstrating that stunting is associated with important metabolic changes, and indicating a higher susceptibility of stunted children to accumulate body fat. In support of this suggestion, Walker et al. ${ }^{7}$ reported that the accumulation of abdominal fat was higher in stunted children with low body mass index (BMI) and low body fat, compared with that of normal stature. Moreover, Martins et al. ${ }^{8}$ demonstrated that stunted adolescents of both genders from a poor area showed greater body fat accumulation and lower lean body mass than those of normal stature. In addition, an investigation carried out in Guatemala established a positive association between stunting in childhood and increased abdominal fat in adulthood. ${ }^{4}$ Lastly, a longitudinal study in Senegal, in which body composition was evaluated using the skinfold method, revealed that stunted adolescent females exhibited increased body fat in the upper body compared with girls of normal stature, independent of total body fat. ${ }^{9}$

Since there is considerable evidence that increased abdominal fat represents a primary factor in body composition for predicting metabolic alterations and noncommunicable diseases, ${ }^{10}$ an early assessment of changes in the distribution of body fat is crucial for implementing strategies in public health

The WHO recommendation of 2008 amends that of 1983 and classifies children and adolescents with HAZ and WAZ between -2 and -1 as normal rather than with mild undernutrition (the previous classification). The hypothesis tested in the present study was that individuals having HAZ within this range present higher body fat content, and therefore should not be categorized as having normal nutritional status. Based on this proposition, this investigation aimed to determine whether pre-pubertal and pubertal individuals with mild stunting ( $<-1$ and $\geq-2 \mathrm{z}$ scores) presented alterations in body composition that were similar to those described for subjects with more severe stunting. If this hypothesis is correct, it would clearly be essential to consider more sensitive cut-off points in the classification of stature, in order to allow an increased vigilance of the metabolic changes that occur in mild nutritional stunting.

\section{Materials and methods}

The study population consisted of 96 pre-pubertal and pubertal individuals in the age range 9 to 19 years who were attending government-funded schools and other institutions located in impoverished areas near the campus of the Universidade Federal de São Paulo (UNIFESP). This study is part of a larger health survey that investigated preadolescents and adolescents with stunting, carried out in the city of São Paulo, with approximately 400 individuals. The sample size of this study was calculated using the statistical odds ratio (OR), with a significance a level of 0.05 , power of 0.80 , sampling ratio of $1: 1$ between exposed and unexposed to the predictor. It was assumed an OR in the source population equal to 2.5 and prevalence of stunted equal to 0.08 among the unexposed population. Due to high costs for assessment of body composition by dualemission X-ray absorptiometry (DXA), it was considered that a sample around $20 \%$ of the survey population was sufficient to test the hypothesis of the study. The maximum acceptable beta error was 0.20 . Subjects were selected for the study according to their nutritional status.

Since the purpose of the study was to detect early changes occasioned by mild stunting, the sample population was divided into two groups according to $H A Z$, namely stunted (HAZ $<-1$ and $\geq-2$ ) and non-stunted (HAZ $\geq$ -1). Participants were further classified as to BMI-for-age percentiles as overweight ( $\geq 85$ th), normal ( $>5$ th and $<$ 85 th), or underweight ( $\leq 5$ th), according to the standard reference values based on the Centers for Disease Control and Prevention (CDC) 2000 growth charts for the United States. ${ }^{11}$

Prior to the commencement of the study, all potential participants were submitted to a clinical examination and anamnesis, as well as laboratory tests, which included blood, urine, and parasitological investigations. Subjects presenting infectious or parasitic diseases were treated according to standard protocols of the Hospital de São Paulo, UNIFESP, and subsequently included in the study.

Individuals diagnosed with genetic syndromes, neurological problems, dementia, or cardiovascular, respiratory or metabolic disorders were excluded from the study, as well as those using corticosteroids or presenting any physical limitations. Participants were examined by a trained pediatrician and classified according to pubertal development by Tanner's ${ }^{12}$ recommendations. Individuals who had attained the appropriate WHO cut-off points (breast stage 2 for girls and genitalia stage 3 for boys) were considered pubertal. ${ }^{13}$ It was not found any individual with early or delayed puberty in the study. Measurements of LH, FSH and testosterone were not done.

The weight of each participant was obtained by single measurement using a Country Technologies (Gays Mills, WI, USA) model SD-150 platform scale with a capacity of 150 $\mathrm{kg}$ and an accuracy of $10 \mathrm{~g}$. Stature was assessed using an AlturExata (TBW, São Paulo, Brazil) portable stadiometer with a precision to the nearest $0.1 \mathrm{~cm}$. BMI values were determined as the quotient between weight and height squared $\left(\mathrm{kg} / \mathrm{m}^{2}\right)$. In order to evaluate waist circumference, subjects were asked to assume a standing position with the abdomen relaxed and arms relaxed alongside the body, and a flexible measuring tape $(0.1 \mathrm{~mm}$ accuracy) was placed horizontally at the midpoint between the bottom 
edge of the last rib and the iliac crest. Measurements were taken with the tape firmly applied on the skin, but without compression of tissues.

Body composition, including fat mass, fat-free soft tissue and abdominal fat, was analyzed by DXA using a Hologic (Bedford, MA, USA) model QDR-4500 A densitometer. A body composition phantom, provided by the manufacturer, was used to calibrate the equipment before each set of measurements. Total body fat and lean mass were estimated with the aid of Hologic enhanced whole body software (version 8.26). The abdominal region of interest was defined manually by adjusting the lines between upper $\mathrm{L} 1$ and lower L4 and the inner costal margin of the whole body scan.

The height-for-age ( $z$ score), BMI $\left(\mathrm{kg} / \mathrm{m}^{2}\right)$ and BMI-forage (percentile) were calculated by the program Epi-Info for Windows, using the National Center for Health Statistics reference. ${ }^{11}$ For nutritional status variables, differences between stature groups were examined by Mann-Whitney test, whilst differences in body composition were calculated using analysis of covariance adjusted for age and weight. The significance level was fixed on 0.05. SPSS for Windows version 16.0 (SPSS, Chicago, IL, USA) was used for statistical analyses.

The study was submitted to, and approved by, the Committee of Ethics in Research of the Universidad Federal de São Paulo (UNIFESP, protocol no. 0284/08). All procedures employed complied with the ethical principles contained in the Declaration of Helsinki as stated by the World Medical Association. Written informed consent was obtained from the participants, or their parents or legal guardians where appropriate, prior to the commencement of the study.

\section{Results}

The study population ( $n=96$ ) comprised $45.8 \%$ females and $54.2 \%$ males. Of the 96 participants, $57.3 \%$ had already reached puberty. The socioeconomic characteristics of the population (Table 1 ) revealed that, although the families of the participants were poor, the mean daily per capita income was above the poverty level (generally considered to be of US\$ 1.25 in the region). However, illiteracy amongst mothers was quite high, at around $11 \%$, and a significant number of homes comprised inadequate shacks built wholly or partly with scrap wood.

Pre-pubertal stunted males presented mean weight, BMI, as well as BMI-for-age percentiles, significantly lower than those of their non-stunted counterparts (Table 2). In pubertal male and pre-pubertal and pubertal female groups, however, there were no significant differences in these parameters between stunted and non-stunted individuals (Table 2). In all groups, HAZ were significantly different, as well as the selection criteria for the groups (Table 2 ). The distribution of the study population according to nutritional status, based on CDC BMI-for-age percentiles, is shown
Table 1 - Socioeconomic characteristics of the study population $(n=96$

\begin{tabular}{lc}
\hline Parameter & Value \\
\hline Schooling (measured as percentage of illiteracy) & \\
$\quad$ Mother & 10.6 \\
Father & 5.6 \\
Family size & $6 \pm 3.6$ \\
Average number of people per dwelling & \\
Income & $484 \pm 328.0$ \\
Monthly family income (US\$) & $4 \pm 2.7$ \\
Daily per capita income (US\$) & \\
Type of abode (\%) & 6.0 \\
Wooden house & 3.9 \\
Wooden + brick house & 90.2 \\
Brick house &
\end{tabular}

in Table 3. With respect to the pre-pubertal groups, the prevalence of overweight among boys was higher than among girls, whereas the opposite was the case for the pubertal groups. In pubertal groups of both genders, the prevalence of overweight was higher among individuals with normal stature compared with stunted individuals.

The results of DXA analyses of body composition of the pre-pubertal and pubertal groups are shown in Table 4. The mean values of body and abdominal fat (in absolute terms and as percentage values) and of waist circumference of stunted pre-pubertal girls were significantly larger than those of non-stunted girls, whilst no differences in any of the evaluated parameters were observed between stunted and non-stunted pre-pubertal boys. Considering the pubertal groups, stunted girls presented significantly higher mean levels of body fat (in absolute terms) and abdominal fat (in absolute terms and as percentage values) in comparison with non-stunted females. A tendency towards larger waist circumference was observed among stunted girls. Pubertal stunted boys, on the other hand, exhibited significantly higher mean levels of body and abdominal fat (in absolute terms and as percentage values), lower fat-free mass (in absolute terms and as percentage), and greater waist circumference in comparison with non-stunted males.

\section{Discussion}

The rate of nutritional transition in developing countries remains a matter of considerable debate, since some studies reveal very rapid shifts from undernutrition to obesity amongst teenagers, 14,15 while others show a clear co-existence of undernutrition and obesity.1,16 The association between undernutrition and obesity is of particular importance, since it has been reported that the combination of undernutrition-related diseases, infections 
and obesity-related syndromes contributes significantly to the disease burden in many countries. ${ }^{1}$

In the past, it has been suggested that children with mild to moderate undernutrition (defined by HAZ and WAZ between -2 and -1 ) are likely to present mortality rates that are more than two-fold higher than those of healthy children. ${ }^{17-19}$ It has also been shown that children with mild undernutrition exhibit impaired immunocompetence and tend to suffer more severe infections than healthy individuals. ${ }^{18,19}$ It is reasonable to expect higher mortality

Table 2 - Nutritional status of the study population

\begin{tabular}{|c|c|c|c|c|c|c|}
\hline \multirow[b]{2}{*}{ Pubertal stage } & \multicolumn{3}{|c|}{ Girls } & \multicolumn{3}{|c|}{ Boys } \\
\hline & Non-stunted* & Stunted $t$ & $\mathbf{p}$ & Non-stunted* & Stunted $t$ & $\mathbf{p}$ \\
\hline Pre-pubertal & $(n=10)$ & $(n=4)$ & & $(n=20)$ & $(n=7)$ & \\
\hline Age (years) & $7.9 \pm 1.4$ & $8.7 \pm 1.0$ & 0.3 & $9.0 \pm 1.7$ & $9.9 \pm 1.3$ & 0.1 \\
\hline Height $(\mathrm{cm})$ & $132.6 \pm 9.0$ & $124.5 \pm 4.1$ & 0.1 & $136.8 \pm 8.7$ & $131.0 \pm 7.3$ & 0.3 \\
\hline Weight (kg) & $28.4 \pm 7.8$ & $25.3 \pm 4.0$ & 0.4 & $36.8 \pm 13.4$ & $25.7 \pm 4.5$ & 0.01 \\
\hline BMI $\left(\mathrm{kg} / \mathrm{m}^{2}\right)$ & $16.0 \pm 3.3$ & $16.3 \pm 1.9$ & 0.7 & $19.1 \pm 4.2$ & $14.9 \pm 2.1$ & 0.01 \\
\hline BMI-for-age percentile & $40.9 \pm 30.6$ & $44.1 \pm 31.8$ & 1.0 & $70.4 \pm 24.3$ & $22.13 \pm 31.7$ & 0.01 \\
\hline HAZ & $0.52 \pm 1.08$ & $-1.6 \pm 0.2$ & 0.01 & $0.13 \pm 0.85$ & $-1.31 \pm 0.23$ & 0.01 \\
\hline Pubertal & $(n=21)$ & $(n=9)$ & & $(n=15)$ & $(n=10)$ & \\
\hline Age (years) & $12.1 \pm 2.6$ & $12.6 \pm 1.0$ & 0.6 & $12.8 \pm 2.3$ & $13.3 \pm 0.9$ & 0.3 \\
\hline Height $(\mathrm{cm})$ & $155.1 \pm 9.4$ & $146.1 \pm 5.2$ & 0.02 & $158.8 \pm 13.4$ & $149.1 \pm 6.1$ & 0.1 \\
\hline Weight (kg) & $56.3 \pm 18.3$ & $48.3 \pm 12.7$ & 0.4 & $50.3 \pm 12.6$ & $42.7 \pm 9.0$ & 0.2 \\
\hline BMI $\left(\mathrm{kg} / \mathrm{m}^{2}\right)$ & $23.0 \pm 5.7$ & $22.4 \pm 5.2$ & 0.8 & $19.7 \pm 3.1$ & $19.2 \pm 3.8$ & 0.7 \\
\hline BMI-for-age percentile & $73.30 \pm 24.36$ & $70.02 \pm 39.50$ & 0.9 & $55.4 \pm 30.2$ & $45.5 \pm 42.7$ & 0.2 \\
\hline HAZ & $0.46 \pm 0.6$ & $-1.6 \pm 0.3$ & 0.01 & $0.3 \pm 0.98$ & $-1.73 \pm 0.14$ & 0.01 \\
\hline
\end{tabular}

$\mathrm{BMI}=$ body mass index; $\mathrm{HAZ}=$ height-for-age $\mathrm{z}$ score.

Values are expressed as mean \pm standard deviation. Mean values were significantly different according to Mann-Whitney test $(p<0.05)$.

* $H A Z \geq-1$.

$+\mathrm{HAZ}<-1$ and $\geq-2$

Table 3 - Nutritional status of the pre-pubertal and pubertal groups classified according to body mass index

\begin{tabular}{|c|c|c|c|c|c|}
\hline \multirow[b]{2}{*}{ Pubertal stage } & \multicolumn{2}{|c|}{ Girls } & \multicolumn{2}{|c|}{ Boys } & \multirow{2}{*}{$\begin{array}{c}\text { Total } \\
\text { n } \\
\text { [row \%] }\end{array}$} \\
\hline & $\begin{array}{c}\text { Non-stunted* } \\
\text { n (column \%) } \\
\text { [row \%] }\end{array}$ & $\begin{array}{c}\text { Stunted }^{+} \\
\text {n (column \%) } \\
\text { [row \%] }\end{array}$ & $\begin{array}{c}\text { Non-stunted* } \\
\text { n (column \%) } \\
\text { [row \%] }\end{array}$ & $\begin{array}{c}\text { Stunted }^{\dagger} \\
\text { n (column \%) } \\
\text { [row \%] }\end{array}$ & \\
\hline \multicolumn{6}{|l|}{ Pre-pubertal } \\
\hline Undernutrition ( $\leq 5$ th percentile) & $1(3.2)[20]$ & & $1(2.8)[20]$ & $3(17.6)[60]$ & $5[100]$ \\
\hline Normal ( $>5$ th to $<85$ th percentile) & $7(22.6)[28]$ & $4(30.8)[16]$ & $10(28.6)[40]$ & $4(23.6)[16]$ & $25[100]$ \\
\hline Overweight ( $\geq 85$ th percentile) & $2(6.5)[18.2]$ & & $9(25.7)[81.8]$ & & $11[100]$ \\
\hline \multicolumn{6}{|l|}{ Pubertal } \\
\hline Undernutrition ( $\leq 5$ th percentile) & & $2(15.4)[40]$ & & $3(17.6)[60]$ & $5[100]$ \\
\hline Normal ( $>5$ th to $<85$ th percentile) & $12(38.7)[44.4]$ & $1(7.7)[3.7]$ & $10(28.6)[37.0]$ & $4(23.6)[14.8]$ & $27[100]$ \\
\hline Overweight ( $\geq 85$ th percentile) & $9(29.0)[39.1]$ & $6(46.1)[26.1]$ & $5(14.3)[21.7]$ & $3(17.6)[13.0]$ & $23[100]$ \\
\hline Total n (column \%) & $31(100)$ & $13(100)$ & $35(100)$ & $17(100)$ & \\
\hline
\end{tabular}

Data based on standard reference of the Centers for Disease Control and Prevention. ${ }^{11}$

${ }^{*}$ Height-for-age $z$ score $\geq-1$.

$\dagger$ Height-for-age $z$ score $<-1$ and $\geq-2$. 
Table 4 - Body composition of the study population

\begin{tabular}{|c|c|c|c|c|c|c|}
\hline \multirow[b]{2}{*}{ Pubertal stage } & \multicolumn{3}{|c|}{ Girls } & \multicolumn{3}{|c|}{ Boys } \\
\hline & Non-stunted* & Stunted $^{+}$ & $\mathbf{p}$ & Non-stunted* & Stunted $^{\dagger}$ & $\mathbf{p}$ \\
\hline Pre-pubertal & $(n=10)$ & $(n=4)$ & & $(n=20)$ & $(n=7)$ & \\
\hline Body fat (kg) & $7.2 \pm 0.6$ & $9.1 \pm 0.8$ & 0.01 & $8.8 \pm 1.8$ & $10.0 \pm 1.8$ & 0.2 \\
\hline Body fat (\%) & $24.5 \pm 1.9$ & $29.9 \pm 2.2$ & 0.03 & $23.3 \pm 4.5$ & $23.2 \pm 5.0$ & 0.1 \\
\hline Lean body mass/height $(\mathrm{g} / \mathrm{cm})$ & $158.0 \pm 10.4$ & $158.2 \pm 11.6$ & 0.9 & $191.1 \pm 12.0$ & $183.2 \pm 13.7$ & 0.2 \\
\hline Fat-free mass (kg) & $20.1 \pm 0.9$ & $18.6 \pm 1.2$ & 0.06 & $24.9 \pm 1.8$ & $23.6 \pm 1.8$ & 0.1 \\
\hline Fat-free mass (\%) & $21.1 \pm 0.9$ & $19.4 \pm 1.2$ & 0.05 & $26.1 \pm 1.8$ & $24.7 \pm 1.8$ & 0.1 \\
\hline Abdominal fat $(\mathrm{kg})$ & $0.4 \pm 0.03$ & $0.7 \pm 0.02$ & 0.03 & $0.5 \pm 0.4$ & $0.6 \pm 0.2$ & 0.3 \\
\hline Abdominal fat (\%) & $20.7 \pm 1.9$ & $27.4 \pm 2.0$ & 0.01 & $20.3 \pm 4.4$ & $20.3 \pm 5.0$ & 0.1 \\
\hline Waist circumference $(\mathrm{cm})$ & $54.7 \pm 1.3$ & $59.7 \pm 2.6$ & 0.02 & $61.8 \pm 4.4$ & $61.5 \pm 5.3$ & 0.9 \\
\hline Pubertal & $(n=21)$ & $(n=9)$ & & $(n=15)$ & $(n=10)$ & \\
\hline Body fat $(\mathrm{kg})$ & $17.1 \pm 2.7$ & $19.9 \pm 2.7$ & 0.01 & $8.6 \pm 2.7$ & $13.4 \pm 2.8$ & 0.01 \\
\hline Body fat (\%) & $30.4 \pm 5.0$ & $33.6 \pm 5.1$ & 0.1 & $18.1 \pm 4.6$ & $26.3 \pm 4.7$ & 0.01 \\
\hline Lean body mass/height $(\mathrm{g} / \mathrm{cm})$ & $231.4 \pm 21.1$ & $245.8 \pm 21.3$ & 0.1 & $246.4 \pm 12.0$ & $243.2 \pm 12.3$ & 0.5 \\
\hline Fat-free mass (kg) & $34.4 \pm 3.20$ & $34.8 \pm 3.0$ & 0.7 & $37.8 \pm 1.93$ & $34.6 \pm 1.9$ & 0.02 \\
\hline Fat-free mass $(\%)$ & $36.1 \pm 3.20$ & $36.4 \pm 3.3$ & 0.8 & $39.7 \pm 1.93$ & $36.3 \pm 2.2$ & 0.01 \\
\hline Abdominal fat $(\mathrm{kg})$ & $1.2 \pm 0.5$ & $1.6 \pm 0.3$ & 0.02 & $0.4 \pm 0.4$ & $0.7 \pm 0.3$ & 0.01 \\
\hline Abdominal fat (\%) & $29.8 \pm 6.9$ & $37.6 \pm 6.9$ & 0.01 & $15.7 \pm 5.0$ & $24.6 \pm 5.4$ & 0.01 \\
\hline Waist circumference $(\mathrm{cm})$ & $71.8 \pm 6.4$ & $77.0 \pm 6.3$ & 0.06 & $66.2 \pm 4.6$ & $73.4 \pm 4.7$ & 0.01 \\
\hline
\end{tabular}

Values are expressed as mean \pm standard deviation. Mean values were significantly different according to analysis of covariance ( $p<0.05$; adjusted for age and weight).

* Height-for-age $z$ score $\geq-1$.

$\dagger$ Height-for-age $z$ score $<-1$ and $\geq-2$.

rates among children with mild undernutrition in comparison to normal children, since they are more likely to descend into severe undernutrition than their healthy counterparts. ${ }^{17}$ Additionally, Rao et al. ${ }^{19}$ have reported that between 16 to $80 \%$ of all nutrition-related deaths are associated with mild to moderate undernutrition rather than with severe undernutrition. The same authors described that $85 \%$ of Indian children suffer from mild to moderate undernutrition while only $10 \%$ are severely malnourished.

According to the most recent WHO standards, preadolescent and adolescent subjects presenting HAZ and WAZ in the range between -2 and -1 are now considered normal, ${ }^{20}$ whereas previous standards considered $z$ scores between these limits to represent mild undernutrition. ${ }^{21}$ Probably the concern regarding mild undernutrition, which formed the basis of earlier studies, has now diminished owing to a worldwide reduction in the prevalence of undernutrition and to an increase in obesity amongst children and adolescents. However, accurate and precise cut-off points are very important in the early detection of nutritional disorders, since they allow rapid intervention and also assist in avoiding or minimizing the development of such conditions and the consequent risk of contracting non-communicable diseases in later life.
Previous studies have shown that moderate to severely undernourished pre-adolescent and adolescent subjects exhibit alterations in body composition. $4,5,8$ In order to examine the hypothesis that pre-adolescent and adolescent subjects with mild undernutrition also exhibit alterations in body composition, body fat, abdominal fat, fat-free mass, and lean body mass/height have been determined in prepubertal and pubertal individuals presenting HAZ in the range between $<-1$ and $\geq-2$.

In the present study, the stature of the parents of the participants was not taken into consideration, since many reports have demonstrated that genetic profile is only useful as a predictor of offspring stature for high socioeconomic groups, within which the growth potential can be fully expressed.22,23 In low socio-economic groups, however, parental stunting may arise from the cumulative effect of poverty endured by several family generations. As recognized by WHO and other authors, stunting may be considered primarily as a good measure of overall social deprivation. 24,25

The results reported herein showed that pre-pubertal stunted girls, but not boys, presented higher average body and abdominal fat content and larger waist circumference in comparison with their counterparts of normal stature (in 
spite of the small number of individuals in the female prepubertal groups), independent of BMI. Within the pubertal groups, stunted girls showed a greater accumulation of abdominal fat than non-stunted females, while stunted boys presented higher body and abdominal fat content, and also larger waist circumference, than their non-stunted counterparts. It has been reported that waist circumference is more representative of central adiposity than BMI. And is a better parameter for indicating morbidity and risk factors. ${ }^{26}$ In the present study, both waist circumference and abdominal fat in pubertal individuals were evaluated in order to improve the diagnosis of central adiposity.

Among stunted individuals, only pubertal girls showed percentage of body fat (33\%) above recommended means $(30 \%)$ for gender and age. ${ }^{27}$ Non-stunted pubertal girls showed a lower value, but within the maximum limit of $30 \%$ that could be considerate inadequate or excessive for the age. ${ }^{28}$ In addition, it called our attention the fact that a high percentage of pre-pubertal non-stunted boys and pubertal non-stunted girls were diagnosed as overweight. The higher percentage of overweight pre-pubertal non-stunted boys (mean percentile 70.4) could be explained by the typical "fat wave" at this age group that disappears with the onset of puberty, as seen for the pubertal group.

A number of researchers $4,8,9$ have reported associations between stunting, accumulation of abdominal fat and lower levels of lean body mass in Guatemalan, Brazilian and African youngsters, and such findings are similar to those presented in this study. It is important to emphasize, however, that, in these studies, more rigorous cut-off points were employed to diagnose stunting. Our results show, however, that metabolic changes such as increased abdominal fat can be observed using a cut-off point that includes mild cases of stunting. On this basis, it is clearly essential to consider more sensitive cut-off points $(<-1$ and $\geq-2$ z scores) in the classification of stature, in order to allow an increased vigilance of the metabolic changes that occur in mild nutritional stunting.

It has been proposed that nutritional deprivation during the fetal period and early childhood may lead to adaptations that could result in the development of obesity during later life. ${ }^{15}$ The results presented herewith not only support this hypothesis, but further suggest that the alterations in metabolism and body composition observed during the prepubertal and pubertal stages of development may predict the later development of non-communicable diseases.

In summary, pre-pubertal and pubertal stunted girls and pubertal stunted boys showed mean levels of abdominal fat that were significantly higher than those of their nonstunted counterparts. Additionally, pre-pubertal and pubertal stunted males exhibited increased body fat in comparison with their corresponding non-stunted groups. These results show that it is possible to detect significant changes in body composition, particularly with respect to abdominal fat, in adolescents with mild stunting ( $\mathrm{HAZ}<-1$ and $\geq-2$ ). It is imperative, therefore, to diagnose and treat teenagers presenting mild stunting in order to preclude or minimize negative consequences in later life.

\section{Acknowledgments}

The authors wish to thank the Fundação de Amparo à Pesquisa do Estado de São Paulo and the International Atomic Energy Agency for sponsoring the study.

\section{References}

1. Black RE, Allen LH, Bhutta ZA, Caulfield LE, de Onis M, Ezzati M, et al. Maternal and child undernutrition: global and regional exposures and health consequences. Lancet. 2008;371:243-60.

2. Corvalan C, Gregory CO, Ramirez-Zea M, Martorell R, Stein AD. Size at birth, infant, early and later childhood growth and adult body composition: a prospective study in a stunted population. Int J Epidemiol. 2007;36:550-7.

3. Hoffman DJ, Sawaya AL, Coward WA, Wright A, Martins PA, de Nascimento $C$, et al. Energy expenditure of stunted and nonstunted boys and girls living in the shantytowns of São Paulo, Brazil. Am J Clin Nutr. 2000;72:1025-31.

4. Schroeder DG, Martorell R, Flores R. Infant and child growth and fatness and fat distribution in Guatemalan adults. Am J Epidemiol. 1999; 149:177-85.

5. Hoffman DJ, Martins PA, Roberts SB, Sawaya AL. Body fat distribution in stunted compared with normal-height children from the shantytowns of São Paulo, Brazil. Nutrition. 2007;23:640-6.

6. Prentice AM. The emerging epidemic of obesity in developing countries. Int J Epidemiol. 2006;35:93-9.

7. Walker SP, Gaskin PS, Powell CA, Bennett FI. The effects of birth weight and postnatal linear growth retardation on body mass index, fatness and fat distribution in mid and late childhood. Public Health Nutr. 2002;5:391-6.

8. Martins PA, Hoffman DJ, Fernandes MT, Nascimento CR, Roberts $\mathrm{SB}$, Sesso R, et al. Stunted children gain less lean body mass and more fat mass than their non-stunted counterparts: a prospective study. Br J Nutr. 2004;92:819-25.

9. Benefice E, Garnier D, Simondon KB, Malina RM. Relationship between stunting in infancy and growth and fat distribution during adolescence in Senegalese girls. Eur J Clin Nutr. 2001;55:50-8.

10. Neovius M, Rossner SM, Vagstrand K, von Hausswolff-Juhlin $Y L$, Hoffstedt J, Ekelund U. Adiposity measures as indicators of metabolic risk factors in adolescents. Obes Facts. 2009;2:294-301.

11. Ogden CL, Kuczmarski RJ, Flegal KM, Mei Z, Guo S, Wei R, et al. Centers for Disease Control and Prevention 2000 growth charts for the United States: improvements to the 1977 National Center for Health Statistics version. Pediatrics. 2002;109:45-60.

12. Tanner JM. The development of the reproductive system. In: Growth at adolescence. 2nd ed. Oxford: Blackwell; 1962. p.28-39.

13. Word Health Organization. Physical Status: the use and interpretation of anthropometry. Infants and Children. Technical Report Series no. 854. Geneva: WHO, 1995.

14. Albala C, Vio F, Kain J, Uauy R. Nutrition transition in Latin America: the case of Chile. Nutr Rev. 2001;59:170-6.

15. Popkin BM. The nutrition transition in low-income countries: an emerging crisis. Nutr Rev. 1994;52:285-98.

16. Lanigan J, Singhal A. Early nutrition and long-term health: a practical approach. Proc Nutr Soc. 2009;68:422-9.

17. Martorell R, Ho TJ. Malnutrition, morbidity, and mortality. Popul Dev Rev. 1984;10 Suppl:49-68. 
18. Pelletier DL. The relationship between child anthropometry and mortality in developing countries: implications for policy, programs and future research. J Nutr. 1994;124:2047S-81S.

19. Rao VG, Sugunan AP, Murhekar MV, Sehgal SC. Malnutrition and high childhood mortality among the Onge tribe of the Andaman and Nicobar Islands. Public Health Nutr. 2006;9:19-25.

20. World Health Organization. The WHO Child Growth Standards. http://www.who.int/childgrowth/en/. Access: June 2010.

21. World Health Organization. Measuring change in nutritional status. Guidelines for assessing the nutritional impact of supplementary feeding programme. Geneva: WHO; 1983.

22. Amigo $H$, Bustos P. Risk factors of short stature in Chilean school children from rural areas of high social vulnerability. Arch Latinoam Nutr. 1995;45:97-102.

23. Voss LD, Mulligan J, Betts PR. Short stature at school entry - an index of social deprivation? (The Wessex Growth Study). Child Care Health Dev. 1998;24:145-56.

24. Florencio TT, Ferreira HS, Cavalcante JC, Sawaya AL. Short stature, obesity and arterial hypertension in a very low income population in north-eastern Brazil. Nutr Metab Cardiovasc Dis. $2004 ; 14: 26-33$
25. Law CM, Shiell AW. Is blood pressure inversely related to birth weight? The strength of evidence from a systematic review of the literature. J Hypertens. 1996;14:935-41.

26. Bergmann GG, Gaya A, Halpern R, Bergmann ML, Rech RR, Constanzi $C B$, et al. Waist circunference as screening instrument for cardiovascular disease risk factors in schoolchildren. J Pediatr (Rio J). 2010;86:411-6.

27. Lohman TG. Advances in body composition assessment. Champaign, IL: Human Kinetics, 1992.

28. Alwis G, Rosengren B, Stenevi-Lundgren S, Düppe $H$, Sernbo I, Karlsson MK. Normative dual energy X-ray absorptiometry data in Swedish children and adolescents. Acta Paediatr. 2010; 99:1091-9.

\section{Correspondence:}

Ana Paula Grotti Clemente

Rua Botucatu, 862, $2^{\circ}$ andar

CEP 04023-060 - São Paulo, SP - Brazi

Tel.: + 55 (11) 5083.2108

E-mail: ana.clemente@unifesp.br 